\title{
QUALIDADE FISIOLÓGICA E SANITÁRIA DE SEMENTES DE MAMONA SUBMETIDAS A DIFERENTES TRATAMENTOS QUÍMICOS ${ }^{1}$
}

\author{
Leandro Tropaldi², Jaine Aparecida de Camargo ${ }^{3}$, Ronny Clayton Smarsi ${ }^{4}$, \\ Stela Maris Kulczynski ${ }^{5}$, Cristina Gonçalves de Mendonça ${ }^{6}$, Manoel Murilo Macedo Barbosa ${ }^{7}$
}

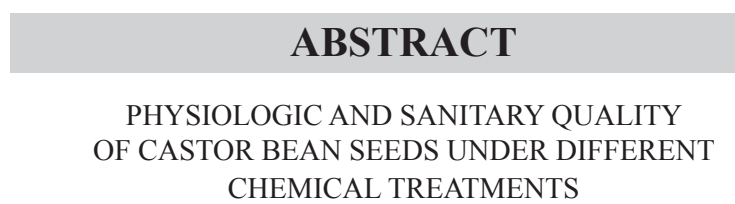

The use of fungicides for treating seeds has become an essential measure in the control of pathogens. However, the effectiveness of many products is not well-known to some crops. The objective of this research was to evaluate the effect of different doses of carbendazin and carboxin + thiram fungicides for controlling pathogens and their interference on the physiologic quality of castor bean seeds. The test consisted of the following treatments (g i.a./100 kg of seeds): carbendazin $(15,30$, and 60$)$, carboxin + thiram $(25+25$, $50+50$, and $100+100)$, formol $0.15 \%(\mathrm{v} / \mathrm{v})$, and control (distilled water). The physiologic quality of the seeds was determined by germination, first counting, field emergence, speed emergence index, length, fresh and dry weight of the aerial part, and electrical conductivity. There were no statistical differences for germination and fresh and dry matter index. The treatment with formol provided lower values for first counting and field emergence. Seeds treated with fungicides presented higher values for electrical conductivity, but did not differ, statistically, among themselves. The fungi Cladosporium spp.; Bipolaris spp.; Curvularia spp.; Aspergillus flavus; Aspergillus niger; Rhizopus sp.; Penicillium sp.; Rhizoctonia sp.; Verticillium sp.; Fusarium sp.; Arthrobotrys sp.; and Epicocum sp. were identified. All tested products, independently of the dose, provided efficient control for pathogens.

KEY-WORDS: Ricinus communis L.; seeds pathogens; carbendazim; carboxim; thiram.

\section{RESUMO}

O tratamento de sementes com fungicidas tornou-se medida indispensável no controle de patógenos. Entretanto, a eficácia de muitos produtos ainda não é bem conhecida para algumas culturas. Este trabalho teve por objetivo avaliar o efeito de diferentes doses dos fungicidas carbendazim e carboxim + thiram no controle de patógenos e sua interferência sobre a qualidade fisiológica em sementes de mamona. O ensaio foi constituído dos seguintes tratamentos (gramas do ingrediente ativo por $100 \mathrm{~kg}$ de sementes): carbendazim (15, 30 e 60), carboxim + thiram $(25+25,50+50,100+100)$, formoldeído $0,15 \%(\mathrm{v} / \mathrm{v})$ e testemunha (água destilada). A qualidade fisiológica das sementes foi determinada pela germinação, primeira contagem, emergência a campo, índice de velocidade de emergência (IVE), número de folhas, comprimento, massa verde e seca da parte aérea e condutividade elétrica. Não houve diferenças estatísticas entre os tratamentos, nas avaliações de germinação, IVE, número de folhas, comprimento, massa verde e seca da parte aérea. O tratamento com formoldeído, se comparado aos demais, proporcionou menores médias $(\mathrm{p}<0,05)$ para a primeira contagem e emergência a campo. Sementes tratadas com fungicidas apresentaram maior condutividade elétrica. Os fungos identificados foram Cladosporium spp.; Bipolaris spp.; Curvularia spp.; Aspergillus flavus; Aspergillus niger; Rhizopus sp.; Penicillium sp.; Rhizoctonia sp.; Verticillium sp.; Fusarium sp.; Arthrobotrys sp.; e Epicocum sp. Os produtos testados, independentemente das doses, promoveram eficiente controle dos patógenos.

PALAVRAS-CHAVE: Ricinus communis L.; patógenos de sementes; carbendazim; carboxim; thiram.

1. Trabalho recebido em fev./2009 e aceito para publicação em mar./2010 (n registro: PAT 5586/ DOI: 10.5216/pat.v40i1.5586).

2. Universidade Estadual Paulista "Júlio de Mesquita Filho" (Unesp), Faculdade de Ciências Agronômicas, Departamento de Agricultura, Botucatu, SP, Brasil.E-mail: tropaldi@ibest.com.br.

3. Universidade Estadual Paulista "Júlio de Mesquita Filho" (Unesp), Faculdade de Engenharia de Ilha Solteira, Departamento de Fitotecnia, Tecnologia de Alimentos e Socioeconomia, Ilha Solteira, SP, Brasil.E-mail: inecamargo_agr@hotmail.com. 4. Instituto Agronômico de Campinas (IAC), Programa de Pós-Graduação do IAC, Campinas, SP, Brasil.

$$
\text { E-mail: ronnycs1@hotmail.com. }
$$

5. Universidade Federal de Santa Maria (UFSM), Centro de Ensino Superior do Rio Grande do Sul, Departamento de Agronomia, Frederico Westphalen, RS, Brasil.E-mail: stelamk@terra.com.br.

6. Universidade Federal do Paraná (UFPR), Setor de Ciências Agrárias, Curitiba, PR, Brasil.

E-mail: cristianemendonca@hotmail.com.

7. Universidade Estadual do Mato Grosso do Sul (UEMS), Unidade Universitária de Cassilândia, Departamento de Agronomia, Cassilândia, MS, Brasil.E-mail: manoel_agro@hotmail.com. 


\section{INTRODUÇÃO}

A mamoneira (Ricinus communis L.) é uma oleaginosa que vem ganhando grande importância no cenário nacional, principalmente devido ao crescente interesse na utilização de fontes de energia renováveis. Como produto principal, é extraído o óleo de seu fruto, sendo este utilizado em ampla gama de produtos industriais e, atualmente, como matériaprima para produção de biodiesel. Como coproduto, há, ainda, a torta, que pode ser utilizada como adubo orgânico. Dessa forma, o fruto da mamoneira pode possuir aproveitamento integral (Santos et al. 2001, Beltrão et al. 2003).

A ricinocultura começou a ser explorada no Cerrado das regiões Nordeste e Centro-Oeste, em sistemas totalmente mecanizados, devido aos trabalhos de melhoramento genético para obtenção de variedades híbridas, como a Lyra, Savana e Sara, que reúnem, como principais características, o baixo porte, precocidade da colheita e produção de frutos indeiscentes.

Para o bom estabelecimento da cultura, associado a uma produção satisfatória, a utilização, no plantio, de sementes de qualidade é de suma importância. Marcos Filho (1994) descreve que a qualidade de um lote de sementes é expressa por uma série de características que determinam o seu valor para semeadura, sendo as mais relevantes as de natureza genética, fisiológica e sanitária.

A capacidade potencial de uma semente originar, em condições favoráveis, uma planta perfeita e vigorosa é denominada qualidade fisiológica. Já a qualidade sanitária representa a ausência de patógenos, incluindo fungos, bactérias e vírus, que, além de influenciar negativamente a emergência, constituem o inóculo primário, que, em condições de ambiente favorável, podem originar graves epidemias (Popinigis 1985, Vieira \& Rava 2000). Atualmente, o tratamento químico de sementes constitui-se em medida indispensável para muitas espécies, assumindo grande importância na produção agrícola, principalmente no controle de patógenos veiculados à semente (Machado 1988).

O tratamento de sementes pode ser visto como uma tecnologia que promove um seguro de baixo custo da cultura, garantindo o máximo rendimento e evitando a introdução de doenças nos anos seguintes. Para algumas culturas anuais de grande importância econômica, o tratamento de sementes é uma prática comum, com vários produtos registrados pelo Ministério da Agricultura, Pecuária e Abastecimento (MAPA). No entanto, para a cultura da mamona, inexistem produtos químicos registrados, que sejam recomendados para o tratamento de sementes (Brasil 2009).

O cultivo de híbridos de mamona, no Cerrado brasileiro, surgiu com a proposta de uma atividade alternativa para o cultivo de safrinha. Assim, o produtor mantém sua atividade principal e a oleaginosa complementa o sistema produtivo da propriedade. Por essa razão, nos últimos anos, a cultura da mamona tem despertado a preocupação de vários pesquisadores, que vêm trabalhando com o tratamento de sementes com diversos produtos químicos, como Beltrão et al. (2003), Poletine et al. (2004), Queiroz et al. (2004), Fernandes et al. (2005) e Ferreira et al. (2006). Normalmente, nos trabalhados já realizados, foram utilizados produtos químicos recomendados para a soja, algodão, feijão e trigo, dentre outras culturas de importância econômica. Entre os produtos utilizados, os ingredientes ativos carbendazim e carboxim + thiram apresentaram maior eficiência no controle de patógenos veiculados pelas sementes de mamona (Poletine et al. 2004, Queiroz, et al. 2004, Fernandes et al. 2005, Ferreira et al. 2006, Marroni et al. 2007 e Santos Neto et al. 2008), mantendo a qualidade fisiológica das sementes.

Morroni et al. (2007) observaram mudanças na qualidade fisiológica, quando trabalharam com duas doses de alguns fungicidas, no tratamento de sementes de mamona, evidenciando que diferentes doses de um mesmo produto químico podem influenciar o vigor e o desenvolvimento das plântulas de mamona. No entanto, trabalhos realizados para determinação de doses ainda são escassos, o que reforça a necessidade da realização de trabalhos com o intuito de determinar produtos e doses eficientes, visto que a cultura vem recebendo incentivo para sua produção, em diversas áreas do país.

Neste contexto, o trabalho teve como objetivo determinar as melhores doses dos produtos químicos de maior eficiência no controle de patógenos veiculados a sementes de mamona e sua interferência na qualidade fisiológica.

\section{MATERIAL E MÉTODOS}

O experimento foi conduzido nas instalações da Universidade Estadual do Mato Grosso do Sul 
(UEMS), Unidade de Cassilândia, de setembro a novembro de 2006, utilizando-se sementes de mamona, cultivar Lyra, oriundas da safra 2005/2006.

Estudou-se o efeito de oito tratamentos (Tabela 1) na qualidade fisiológica e sanitária de sementes de mamona. Para os tratamentos testemunha (água destilada) e formol, o procedimento utilizado foi semelhante, ou seja, as subamostras de sementes de mamona foram imersas, durante 20 minutos, na solução de água destilada ou formol e secas sobre papel toalha, ao ar livre. Para os tratamentos com fungicidas, adicionou-se o produto químico à subamostra de sementes, agitando-as dentro de um saco plástico, até sua homogeneização, sendo, posteriormente, secas ao ar livre, sobre papel toalha.

Após o tratamento das sementes, foram avaliadas as seguintes variáveis: germinação, primeira contagem de germinação, emergência de plântulas e índice de velocidade de emergência a campo, além do vigor de plântulas e condutividade elétrica das sementes, após os tratamentos.

A germinação foi realizada em rolos de papel germitest, umedecido com água, na quantidade equivalente a 2,5 vezes o peso do substrato seco, e incubado, em incubadora tipo $\mathrm{BOD}$, à temperatura $25^{\circ} \mathrm{C} \pm 2{ }^{\circ} \mathrm{C}$, umidade relativa do ar de $85 \%$ e fotoperíodo de 12 horas. Utilizaram-se 200 sementes por tratamento, divididas em quatro repetições. A contagem da germinação e do número de plântulas normais foi realizada aos quatorze dias após o estabelecimento do teste. A Primeira contagem de germinação foi conduzida em conjunto com o teste de germinação, sendo a avaliação realizada aos sete dias e considerando-se apenas o número de plântulas normais. O Índice de velocidade de emergência (IVE) foi obtido utilizando-se 100 sementes de cada tratamento, com quatro repetições de 25 sementes, semeadas a campo a $0,05 \mathrm{~m}$ de profundidade. Foram realizadas contagens diárias do número de plântulas emergidas, considerando-se aquelas que apresentavam dois folíolos completamente abertos, até a estabilização do estande. Calculou-se, então, o IVE (Maguire 1962). O vigor de plântulas foi determinado em 10 plântulas, escolhidas aleatoriamente, sendo estas cortadas no colo, e foram avaliados o número de folhas, comprimento ( $\mathrm{cm}$ ), massa fresca e seca da parte aérea $(\mathrm{g})$. A Emergência de plântulas a campo foi conduzida juntamente com o índice de velocidade de emergência, sendo as avaliações realizadas aos 21 dias após a semeadura, determinando-se a percentagem total de plântulas emergidas. No teste de condutividade elétrica, foram utilizadas 100 sementes de cada tratamento, em quatro repetições de 25 sementes. As mesmas foram incubadas, por 24 horas, à temperatura de $25^{\circ} \mathrm{C} \pm 2^{\circ} \mathrm{C}$, em $\mathrm{BOD}$, utilizando-se copos descartáveis, com $75 \mathrm{~mL}$ de água deionizada. A aferição foi realizada com condutivímetro elétrico, marca MARCONI CA 150, e os valores obtidos no aparelho foram divididos pelo peso da amostra, sendo os resultados expressos em $\mu \mathrm{S} \mathrm{cm}^{-1} \mathrm{~g}^{-1}$ de sementes.

A análise sanitária foi realizada pelo método do papel filtro (Blotter Test), utilizando-se 200 sementes por tratamento, divididas em quatro subamostras de 50 sementes. Após sete dias de incubação, foram avaliadas as populações dos patógenos presentes nas sementes, com resultado expresso em percentagem. A identificação dos fungos presentes nas sementes foi realizada com o auxílio de uma lupa e, quando necessário, recorreu-se ao microscópio estereoscópio, para visualização de estruturas e identificação pela chave de classificação, apenas até o grupo genérico, para a maioria.

Tabela 1. Descrição dos tratamentos avaliados no experimento (Cassilândia, MS, 2006).

\begin{tabular}{lclc}
\hline Ingrediente ativo & Dose & Nome químico & Nome comercial \\
\hline Testemunha & - & Água destilada & - \\
\hline Formol & $0,15^{1}$ & Formaldeído & - \\
\hline Carbendazim & $15^{2}$ & & \\
Carbendazim & $30^{2}$ & Methyl benzimidazol-2-ylcarbamate & Derosal 500 SC \\
Carbendazim & $60^{2}$ & & \\
\hline Carboxim + thiram & $25+25^{2}$ & & \\
Carboxim + thiram & $50+50^{2}$ & 5,6 -dihydro-2 methyl-1,4-oxatiina-3-carboxanilida + & Vitavax-Thiram 200 SC \\
Carboxim + thiram & $100+100^{2}$ & dissulfeto de tetrametiltiuram & \\
\hline \% (v/v). & & \\
$2 \mathrm{~g}$ ingrediente ativo por $100 \mathrm{~kg}$ de sementes. &
\end{tabular}


Os dados foram submetidos a análise de variância e as médias foram comparadas pelo teste Tukey, a $5 \%$ de probabilidade, utilizando-se o programa estatístico SISVAR.

\section{RESULTADOS E DISCUSSÃO}

Na Tabela 2, encontram-se os resultados das avaliações, para cada tratamento de germinação, primeira contagem, emergência a campo, índice de velocidade de emergência (IVE) e vigor de plântulas, avaliados por meio do número de folhas, altura da parte aérea, massa fresca e seca da parte aérea. Observou-se que as médias de germinação, IVE, número de folhas, altura, matéria fresca e seca da parte aérea não apresentaram diferenças entre os tratamentos avaliados.

O tratamento químico das sementes foi ineficiente para promover uma maior germinação de sementes. Isto pode ser explicado pelas altas médias de germinação obtidas com o lote de sementes avaliado (90\% a 95\%), que podem ter contribuído para anular o efeito dos fungicidas, na qualidade fisiológica das sementes. Dhingra \& Açuña (1997) relataram que, em sementes de soja, o tratamento de sementes só traz efeitos benéficos imediatos na germinação de sementes de má qualidade, não aumentando a taxa de germinação das sementes de boa qualidade. Segundo Morroni et al. (2007), a germinação pode ser influenciada pelo tratamento químico e pela qualidade inicial dos lotes.
Apenas para as variáveis primeira contagem e emergência de plântulas a campo, foram verificadas diferenças significativas entre os tratamentos. $\mathrm{Na}$ primeira contagem, o menor índice de germinação (43\%) foi observado no tratamento com formol a $0,15 \%$, sendo, porém, estatisticamente igual ao tratamento com carbendazim 60 (Tabela 2). Tendência semelhante foi observada para o teste de emergência a campo.

Nas comparações entre os tratamentos do índice velocidade de emergência e do vigor de plântulas a campo, mensurado através do número de folhas, altura, massa fresca e seca da parte aérea, não verificaram-se diferenças significativas entre as médias, para nenhum dos tratamentos $(\mathrm{p}<0,05)$ (Tabela 2). Possivelmente, as condições ambientais não tenham sido favoráveis ao desenvolvimento e crescimento de patógenos, sejam eles oriundos das sementes ou do solo, o que refletiu no desenvolvimento normal, sem danos, das plântulas de mamoneira. Também, o alto vigor das sementes utilizadas pode ter contribuído para o bom desenvolvimento das plântulas a campo. De acordo com Marcos Filho (1994), o desempenho de plantas em campo é atribuído ao potencial fisiológico inicial das sementes, principalmente em condições de estresse.

Outro parâmetro avaliado foi a condutividade elétrica (Tabela 3). Aguilera et al. (2000) questionam a metodologia desse teste, quando aplicado a sementes tratadas quimicamente, visto que o tratamento

Tabela 2. Médias de germinação $(\mathrm{G})$; primeira contagem (PC); emergência de plântulas a campo (EPC); índice de velocidade de emergência a campo (IVE); e vigor de plântulas - número de folhas (NF), altura da parte aérea (APA), massa fresca (MF) e seca (MS), em função de diferentes tratamentos das sementes de mamona (Ricinus Communis L.) (Cassilândia, MS, 2006).

\begin{tabular}{|c|c|c|c|c|c|c|c|c|}
\hline \multirow{2}{*}{ Tratamentos } & \multirow{2}{*}{ G } & \multirow{2}{*}{$\mathrm{PC}$} & \multirow{2}{*}{ EPC } & \multirow{2}{*}{ IVE } & \multicolumn{4}{|c|}{ Vigor de plântulas } \\
\hline & & & & & NF & APA & MF & MS \\
\hline & 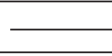 & $-\%-$ & $\overline{-}$ & & & $\mathrm{cm}$ & $\mathrm{g}$ & 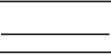 \\
\hline Testemunha & $90 \mathrm{a}^{*}$ & $72,5 \mathrm{a}$ & $90 \mathrm{ab}$ & $6,7 \mathrm{a}$ & $6,2 \mathrm{a}$ & $12,5 \mathrm{a}$ & 197,7 a & $35,7 \mathrm{a}$ \\
\hline Formol $0,15 \%(\mathrm{v} / \mathrm{v})$ & $90 \mathrm{a}$ & $43,0 \mathrm{~b}$ & $83 \mathrm{~b}$ & $5,8 \mathrm{a}$ & $6,2 \mathrm{a}$ & $12,5 \mathrm{a}$ & $178,2 \mathrm{a}$ & $32,7 \mathrm{a}$ \\
\hline Carbendazim 15 & $90 \mathrm{a}$ & $84,0 \mathrm{a}$ & $95 \mathrm{a}$ & $6,5 \mathrm{a}$ & $6,0 \mathrm{a}$ & $13,2 \mathrm{a}$ & $197,2 \mathrm{a}$ & $38,0 \mathrm{a}$ \\
\hline Carbendazim 30 & $93 \mathrm{a}$ & $70,5 \mathrm{a}$ & $94 \mathrm{ab}$ & $7,4 \mathrm{a}$ & $6,2 \mathrm{a}$ & $14,0 \mathrm{a}$ & $206,0 \mathrm{a}$ & $36,5 \mathrm{a}$ \\
\hline Carbendazim 60 & $91 \mathrm{a}$ & $65,0 \mathrm{ab}$ & $95 \mathrm{a}$ & $6,7 \mathrm{a}$ & $6,0 \mathrm{a}$ & $13,0 \mathrm{a}$ & $168,0 \mathrm{a}$ & $31,7 \mathrm{a}$ \\
\hline Carboxim + thiram $25+25$ & $95 \mathrm{a}$ & $83,0 \mathrm{a}$ & $90 \mathrm{ab}$ & $6,4 \mathrm{a}$ & $6,0 \mathrm{a}$ & $14,0 \mathrm{a}$ & $198,2 \mathrm{a}$ & $37,2 \mathrm{a}$ \\
\hline Carboxim+thiram $50+50$ & $95 \mathrm{a}$ & $76,5 \mathrm{a}$ & $96 \mathrm{a}$ & $7,5 \mathrm{a}$ & $6,7 \mathrm{a}$ & $13,5 \mathrm{a}$ & $212,2 \mathrm{a}$ & $40,7 \mathrm{a}$ \\
\hline Carboxim+thiram $100+100$ & $92 \mathrm{a}$ & $71,0 \mathrm{a}$ & $94 \mathrm{ab}$ & $6,9 \mathrm{a}$ & $6,2 \mathrm{a}$ & $13,2 \mathrm{a}$ & $212,7 \mathrm{a}$ & $38,5 \mathrm{a}$ \\
\hline $\mathrm{CV}(\%)$ & 3,56 & 13,99 & 5,25 & 17,15 & 8,88 & 10,32 & 20,26 & 17,08 \\
\hline
\end{tabular}

* Médias seguidas de mesma letra minúscula, na coluna, não diferem entre si pelo Teste Tukey, a 5\% de probabilidade. 
Tabela 3. Condutividade elétrica de sementes de mamona (Ricinus communis L.), em função dos diferentes tratamentos (Cassilândia, MS, 2006).

\begin{tabular}{lc}
\hline Tratamentos & Condutividade elétrica \\
\cline { 2 - 2 } & $\mu \mathrm{S} \mathrm{cm}^{-1} \mathrm{~g}^{-1}$ \\
\hline Testemunha & $1,1 \mathrm{a}^{*}$ \\
Formol 0,15\% $(\mathrm{v} / \mathrm{v})$ & $1,1 \mathrm{a}$ \\
Carbendazim 15 & $2,5 \mathrm{~b}$ \\
Carbendazim 30 & $2,4 \mathrm{~b}$ \\
Carbendazim 60 & $2,5 \mathrm{~b}$ \\
Carboxim + thiram 25+25 & $2,3 \mathrm{~b}$ \\
Carboxim + thiram 50+50 & $2,3 \mathrm{~b}$ \\
Carboxim + thiram 100+100 & $2,2 \mathrm{~b}$ \\
\hline CV (\%) & 5,75 \\
\hline
\end{tabular}

* Médias seguidas de mesma letra minúscula, na coluna, não diferem entre si pelo Teste Tukey, a 5\% de probabilidade.

químico eleva bruscamente a quantidade de solutos na solução, como é confirmado na Tabela 3, onde as sementes submetidas aos tratamentos com água e formol $0,15 \%(\mathrm{v} / \mathrm{v})$ apresentaram valores bastante inferiores aos das sementes tratadas com os demais produtos químicos. Os autores ainda comentam que a comparação entre lotes de sementes tratadas e não tratadas acaba sofrendo interferência, devido à maior liberação de solutos pelos produtos químicos, mascarando as comparações de vigor de lotes de sementes tratadas e não tratadas. Neste caso, sugerese a utilização de outros testes para determinação de vigor de sementes. Poletine et al. (2004) constataram que o tratamento de sementes com fungicida proporcionou aumento de produtividade e enfatizaram que a mistura carboxin + thiram, entre os produtos testados, foi a que proporcionou maior produtividade. Menten (1995) salienta que os efeitos do tratamento de sementes na germinação ocorrem a médio e longo prazo, como acontece, por exemplo, com a diminuição no avanço de desenvolvimento de doenças e/ou introdução de patógenos nas áreas.

$\mathrm{Na}$ análise sanitária das sementes (Tabela 4), os tratamentos com os fungicidas carbendazim e carboxim + thiram, em todas as concentrações, promoveram $100 \%$ de controle de fungos. Já para o tratamento com formol (20 minutos a $0,15 \mathrm{v} / \mathrm{v}$ ), verificou-se alta incidência de fungos associados a sementes de mamona, inviabilizando seu uso como medida efetiva de tratamento de sementes. Com a utilização do formaldeído, por duas horas, em
Tabela 4. Percentagem de contaminação fúngica, em sementes de mamona (Ricinus communis L.), em função dos diferentes tratamentos (Cassilândia, MS, 2006).

\begin{tabular}{lc}
\hline Tratamentos & Contaminação (\%) \\
\hline Testemunha & $100,0 \quad \mathrm{c}^{*}$ \\
Formol 0,15\% (v/v) & $97,2 \mathrm{~b}$ \\
Carbendazim 15 & $0,0 \mathrm{a}$ \\
Carbendazim 30 & $0,0 \mathrm{a}$ \\
Carbendazim 60 & $0,0 \mathrm{a}$ \\
Carboxim + thiram 25+25 & $0,0 \mathrm{a}$ \\
Carboxim + thiram 50+50 & $0,0 \mathrm{a}$ \\
Carboxim + thiram 100+100 & $0,0 \mathrm{a}$ \\
\hline CV (\%) & 4,59 \\
\hline * Médias seguidas de mesma letra minúscula, na coluna, não diferem entre si pelo \\
Teste Tukey, a 5\% de probabilidade.
\end{tabular}

Limonium platyphyllum Lincz, Fior et al. (2001) obtiveram redução da contaminação por fungos. Porém, a regeneração e brotação do material "in vitro" sofreu interferência negativa.

Independentemente dos tratamentos, os principais microorganismos detectados nas sementes de mamona foram Cladosporium spp.; Bipolaris spp.; Curvularia spp.; Aspergillus flavus; Aspergillus niger; Aspergillus sp.; Rhizopus sp.; Penicillium sp.; Rhizoctonia sp.; Verticillium sp.; Fusarium sp.; Arthrobotrys sp.; e Epicocum sp. Segundo Tanaka \& Corrêa (1981), os fungos vinculados pelas sementes, como os encontrados nas sementes de mamona, podem deteriorar as sementes, chegando a provocar queda na germinação e na emergência das plântulas a campo.

Na Tabela 5, encontram-se a lista dos microorganismos e respectivos índices de atividade, nas sementes não tratadas e tratadas com formol. Evidenciou-se que, entre os dois tratamentos em questão, ocorreram algumas diferenças, com relação ao nível de incidência. Sementes não tratadas (testemunha), comparadas às sementes tratadas com formol, apresentaram índices de atividade significativamente superiores $(\mathrm{p}<0,05)$ para os patógenos Cladosporium sp., Aspergillus niger e Pennicilium sp. Em sementes não tratadas, os fungos Aspergillus flavus, A. niger e Penicillium sp., considerados como alguns dos principais fungos de armazenamento (Lucca-Filho 1995), tiveram média incidência, chegando a $31,8 \% ; 29,6 \%$; e $30,5 \%$ das 
Tabela 5. Percentagem de incidência de espécies fúngicas, em sementes de mamona (Ricinus communis L.), após o tratamento das sementes (UEMS/UUC) (Cassilândia, MS, 2006).

\begin{tabular}{|c|c|c|c|c|c|c|c|c|}
\hline \multirow{2}{*}{ Tratamentos } & \multicolumn{8}{|c|}{ Incidência de fungos (\%) } \\
\hline & Cla. ${ }^{1}$ & Bip. & Cur. & Asp. f. & Asp. n. & Pen. & Fus. & Epi. \\
\hline Testemunha & $58,7 \mathrm{a}^{2}$ & $6,7 \mathrm{a}$ & $9,4 \mathrm{a}$ & $31,8 \mathrm{a}$ & $29,6 \mathrm{a}$ & $30,5 \mathrm{a}$ & $3,9 \mathrm{a}$ & $1,3 \mathrm{a}$ \\
\hline Formol $0,15 \%$ & $29,6 \mathrm{~b}$ & $7,9 \mathrm{a}$ & $9,5 \mathrm{a}$ & $42,6 \mathrm{a}$ & $0,0 \quad \mathrm{~b}$ & $13,3 \quad 1$ & $9,2 \mathrm{a}$ & $1,3 \mathrm{a}$ \\
\hline
\end{tabular}

${ }^{1}$ Cla. = Cladosporium spp.; Bip. = Bipolaris spp.; Cur. = Curvularia spp.; Asp. f. = Aspergillos flavus; Asp. n. = Aspergillos niger; Pen. = Penicillium sp.; Fus. = Fusarium sp.; Epi. = Epicocum sp.

${ }^{2}$ Médias seguidas de mesma letra minúscula, na coluna, não diferem entre si pelo Teste Tukey, a 5\% de probabilidade.

sementes, respectivamente. Altos índices de incidência foram observados para Cladosporium sp., chegando a mais de $58 \%$, nas sementes não tratadas.

No que concerne a fungos associados às sementes de mamona, Zaratta et al. (2004) relataram maior incidência dos seguintes gêneros: Fusarium, Penicillium, Alternaria, Rhizopus, Botrytis, Cladosporium e Pestalotia. Os dados discordam, aparentemente, dos verificados no presente trabalho, pois não foi detectada a presença de Botrytis, agente causal do mofo-cinzento, uma das doenças mais problemáticas no cultivo da mamona, responsável por grandes prejuízos. Lima et al. (2001) e Beltrão et al. (2003) mencionam que são vários os fungos potencialmente prejudiciais à mamoneira, sendo as sementes os agentes de disseminação, de uma área para outra, desencadeando epidemias na lavoura ou introduzindo novos problemas na área de cultivo. A presença de Rhizoctonia sp., agente etiológico do tombamento, patógeno de solo que possui uma gama enorme de hospedeiros, reforça a necessidade do tratamento de sementes, a fim de se evitar a introdução de patógenos nas áreas de cultivo.

\section{CONCLUSÃO}

O uso de carbendazim e carboxim + thiram, no tratamento das sementes, independentemente da dose utilizada, proporcionou $100 \%$ de eficiência no controle de patógenos e não foram verificadas interferências negativas na qualidade fisiológica das sementes de mamona.

\section{REFERENNCIAS}

AGUILERA, L.A. et al. Qualidade fisiológica de sementes de milho em função da forma e do tratamento químico das sementes. Ciência Rural, Santa Maria, v.30, n.2, p.211$215,2000$.
BELTRÃO, N. E. M. et al. Mamona: árvore do conhecimento e sistemas de produção para o semi-árido brasileiro. Campina Grande: Embrapa Algodão, 2003. (Circular técnica, n. 70).

BRASIL. Ministério da Agricultura Pecuária e Abastecimento. Agrofit. 2003. Disponível em: <http:// extranet.agricultura.gov.br/agrofit_cons/principal_agrofit_ cons>. Acesso em: 01 nov. 2009.

DHINGRA, O. D.; ACUÑA, R. S. Patologia de sementes de soja. Viçosa: UFV, 1997.

FERNANDES, G. M. B. et al. Efeito da remoção da carúncula e de tratamento fungicida na germinação e vigor de sementes de mamona. In: CONGRESSO BRASILEIRO DE PLANTAS OLEAGINOSAS, ÓLEOS, GORDURAS E BIODIESEL, 2., 2005, Varginha. Anais... Varginha: Ufla, 2005. p. 181-186.

FERREIRA, G. B. et al. A cultura da mamona no Cerrado: riscos e oportunidades. Campina Grande: Embrapa Algodão, 2006. (Documentos, 149).

FIOR, C. S. et al. Assepsia com paraformaldeído no cultivo de discos foliares e segmentos nodais de Limonium platyphyllum Lincz. In: ENCONTRO LATINOAMERICANO DE BIOTECNOLOGIA VEGETAL, 4., 2001, Goiânia. Anais... Goiânia: Redbio, 2001. 1 CDROM.

LIMA, E. F. et al. Doenças e seu controle. In: AZEVEDO, D. M. P.; LIMA, E. F. O agronegócio da mamona no Brasil. Campina Grande: Embrapa Algodão, 2001.p. 191212.

LUCCA-FILHO, O. A. Curso de tecnologia de sementes. Brasília, DF: Abeas, 1995.

MACHADO, J. C. Patologia de sementes: fundamentos e aplicações. Lavras: ESAL/FAEPE, 1988.

MAGUIRE, J. D. Speed of germination-aid in selection and evaluation for seedling emergence and vigor. Crop Science, Madison, v. 2, n. 1, p. 176-177, 1962.

MARCOS FILHO, J. Avaliação da qualidade de sementes. Informativo Abrates, Londrina, v. 4, n. 2, p. 33-35, 1994. 
MARRONI, I. V. et al. Efeito dos tratamentos químico e biológico de sementes de mamona sobre a germinação, emergência e produção de massa seca. In: SIMPÓSIO ESTADUAL DE AGROENERGIA, 1., 2007, Pelotas. Anais... Pelotas: Embrapa Clima Temperado, 2007. 1 CD-ROM.

MENTEN, J. O. M. Patógenos em sementes: detecção, danos e controle químico. São Paulo: Ciba Agro, 1995.

POLETINE, J. P. et al. Avaliação de fungicidas para tratamento de sementes de mamona (Ricinus communis L.). In: CONGRESSO BRASILEIRO DE MAMONA, 1., 2004, Campina Grande. Anais... Campina Grande: Embrapa, 2004. 1 CD-ROM.

POPINIGIS, F. Fisiologia da semente. 2. ed. Brasília, DF: Agiplan, 1985.

QUEIROZ, J. A. et al. Efeito da remoção da carúncula, tratamento químico e tempo de armazenamento na germinação de sementes de mamona (Ricinus communis L.). In: CONGRESSO BRASILEIRO DE MAMONA, 1., 2004, Campina Grande. Anais... Campina Grande: Embrapa, 2004. 1 CD-ROM.

SANTOS, R. F. et al. Análise econômica. In: AZEVEDO, D. M. P.; LIMA, E. F. O agronegócio da mamona no Brasil. Campina Grande: Embrapa Algodão, 2001. p. 17-35.
SANTOS NETO, A. L. et al. Qualidade fisiológica e sanitária de sementes de mamona tratadas com fungicidas. In: CONGRESSO BRASILEIRO DE MAMONA, 3., 2008, Salvador. Anais... Salvador: Embrapa, 2008. 1 CD-ROM.

TANAKA, M. A.; CORRÊA, M. U. Influência de Aspergillus e Penicillium no armazenamento de sementes de feijão (Phaseolus vulgaris L.). Fitopatologia Brasileira, Brasília, DF, v. 6, n. 3, p. 451-456, 1981.

VIEIRA, E. H. N.; RAVA, C. A. (Eds.). Sementes de feijão: produção e tecnologia. Santo Antônio de Goiás: Embrapa Arroz e Feijão, 2000.

ZANATTA, G. C. N. et al. Fungos associados às sementes de seis cultivares de mamoneira (Ricinus communis L.) cultivadas na região de Pelotas, RS, safra 2003/2004. In: CONGRESSO BRASILEIRO DE MAMONA, 1., 2004, Campina Grande. Anais... Campina Grande: Embrapa, 2004. 1 CD-ROM. 